УДК 378.14

DOI: $10.14451 / 1.199 .58$

\title{
ПРОБЛЕМАТИКА ОРГАНИЗАЦИИ ОБРАЗОВАТЕЛЬНОГО ПРОЦЕССА В УСЛОВИЯХ ПАНДЕМИИ
}

\author{
(c) 2021 Пашук Наталья Руслановна
}

старший преподаватель, институт экономики и управления

Владивостокский государственный университет экономики и сервиса, Россия, Владивосток

E-mail: natalia-kravchenko@inbox.ru

(c) 2021 Ставничий Лев Сергеевич

студент, институт экономики и управления

Владивостокский государственный университет экономики и сервиса, Россия, Владивосток

E-mail: stavnichiy999@gmail.com

(c) 2021 Ямковая Алена Евгеньевна

студент, институт экономики и управления

Владивостокский государственный университет экономики и сервиса, Россия, Владивосток

E-mail: lyolya_99@mail.ru

Спонтанная цифровизация образовательного процесса в условиях пандемии в 2020 г. стимулировала рост профессиональных навыков, как преподавателей университетов, так и студенческого сообщества. Однако многие обучающиеся столкнулись с техническими трудностями выполнения заданий при организации дистанционного обучения. Данная работа направлена на установление основных сложностей обучения посредством проведения массового опроса среди студентов.

Ключевые слова: образовательный процесс, пандемия, цифровизация образования, проблемы высшего образования, дистанционное обучение.

Механизм очного обучения в весеннем семестре года 2020 г. потерпел принудительное изменение за счет объемного внедрения дистанционных инструментов в систему образования по причине пандемии. Президент РФ подписал закон о внесении изменений в ФЗ «Об образовании в РФ», что обеспечило возможность перехода на дистанционное обучение в случае введения чрезвычайного положения, режима повышенной готовности или чрезвычайной ситуации. Согласно документу, студенты и аспиранты всех образовательных программ перешли на дистанционное образование с 17 марта 2020 года. Однако не все университеты оказались в полной мере готовы к данным изменениям, а студенты очной формы обучения столкнулись с рядом проблем, так как данный режим оказался им совершенно незнаком и непонятен. Стали появляться трудности с образовательными платформами, представленными для «комфортного» обучения, которое таковым, совершенно не оказалось. Весомая часть студентов-очников не располагали должным оборудованием и средствами для установки программного обеспечения в столь короткие сроки, а удаленная техническая поддержка не всегда могла оперативно обрабатывать волну запросов, поступающих от обучающихся и преподавателей. Также, возникшие трудности обуславливались и отрицательной реакцией преподавательского состава на применение новых для них технологий в процессе обучения, что значительно тормозило освоение образовательных программ студентами.

В связи с этим, основной целью данной работы является исследование проблем образовательного процесса, с которыми столкнулись студенты очной формы обучения.

Для достижения поставленной цели решен комплекс взаимосвязанных задач:

1. проанализирован перечень возможных трудностей организации обучения в период пандемии;

2. сформирован рабочий шаблон анкеты и проведен опрос среди студентов;

3. обработаны результаты опроса, на основании которых сформированы основные рекомендации по совершенствованию процесса обучения.

Объектом исследования является - образовательный процесс Владивостокского государ- 
ственного университета экономики и управления в период с марта по июль 2020 г.

Исследованием проблем организации дистанционного обучения занимались такие ученые как: Балычевцева И.В., Чернышева О.В., Самойлеченко И.Г., Конюшевская А.А., Кривошеева В.В., Герасименко В.В., Полесов Т.Р., Павлов Е.Н., Долинский В.В. [1], Верхотин Д. Г. [2], Москаленко Е. В., Овчаров А. В. [3], Татаринов К.А. [4], Фадеев Е. В. [5], Чигинцева А. А. [6] и мн. др.

По мнению данных ученых, к основным проблемам дистанционного обучения относится недостаток живого общения с преподавателем. Также, не в полной мере развиваются коммуникативные способности. Не все образовательные учреждения могут перейти на электронное обучение, возможно медленное интернет - соединение, отсутствие ПК или веб-камеры.

Авторами отмечен ряд проблем: у слушателей возникает соблазн отложить работу до лучших времен; сложность встраивания мотивационных компонентов (которые должны постоянно поддерживать высокий уровень интереса к процессу); отсутствие навыков самоорганизации учебной деятельности вне прямого контакта с преподавателем; временные ограничения, вопрос доступности их для слушателя в условиях цифрового неравенства регионов России.

Для того, чтобы лучше понять и разобрать все аспекты данной проблемы было проведено анкетирование среди студентов очной формы обучения единовременно перешедших, из-за сложившийся эпидемиологической ситуации, на дистанционный формат. В опросе приняли участие 200 студентов разных направлений обучения. Рассмотрим подробнее ответы респон- дентов на вопросы анкетирования.

Первоначально необходимо было установить, насколько удобен для студентов дистанционный формат обучения (рис. 1).

На основании представленных выше данных, можно сделать вывод, что подавляющему большинству студентов очной формы обучения временное и внезапное внедрение дистанционных инструментов в образовательный процесс показалось неудобным, так как в совокупности только 44 респондента из опрошенных остались удовлетворены уровнем удобства, что в процентном соотношении составляет 22\% опрошенных. Данный факт подтверждает наличие проблем в организации удаленного обучения.

Следующим был задан вопрос об уровне нагрузки в период дистанционного обучения. Результаты представлены на рисунке 2.

По данным исследования видно, что большинство студентов, а именно 84 человека, что в процентном выражении составляет $42 \%$, говорят о стре6мительном увеличении нагрузки в связи с переходом на онлайн обучение. Преподаватели стали увеличивать объем самостоятельной работы для студентов - нагрузка увеличилась почти в два раза. Возьмем в пример дисциплину, связанную с нашим здоровьем - физическая культура. Вместо привычных всем упражнений и разминки студенты пишут рефераты и выполняют уйму письменных заданий. Но, также есть студенты, которые считают, что нагрузка совершенно не изменилась.

Немаловажным показателем является профессионализм преподавателей и их способность оперативно решить сложившиеся трудности в адаптации к новой форме обучения. В связи с

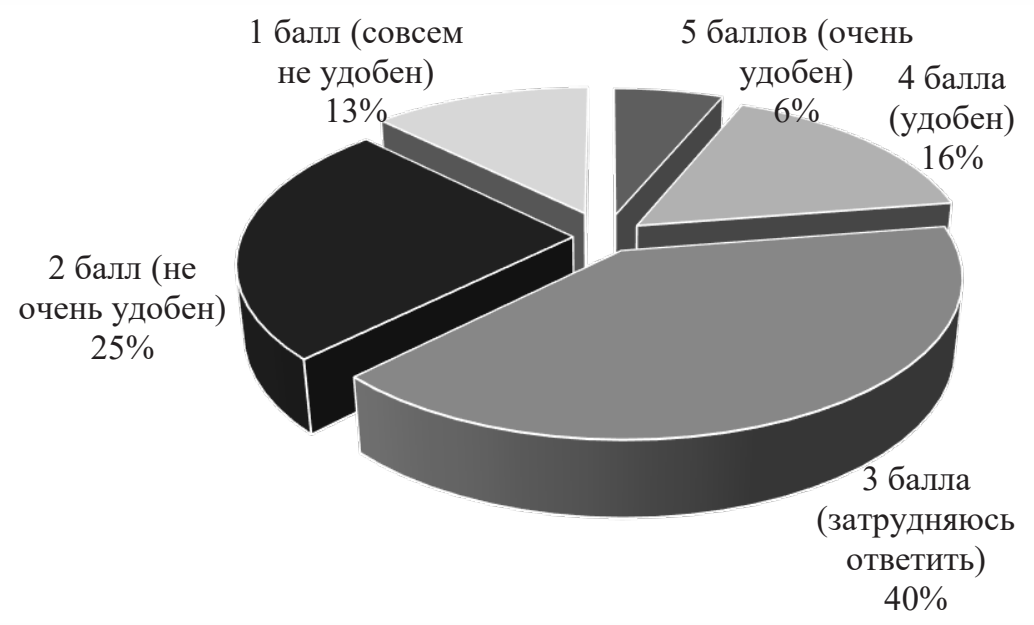

Рисунок 1. Удобство использования дистанционных инструментов обучения в период пандемии 


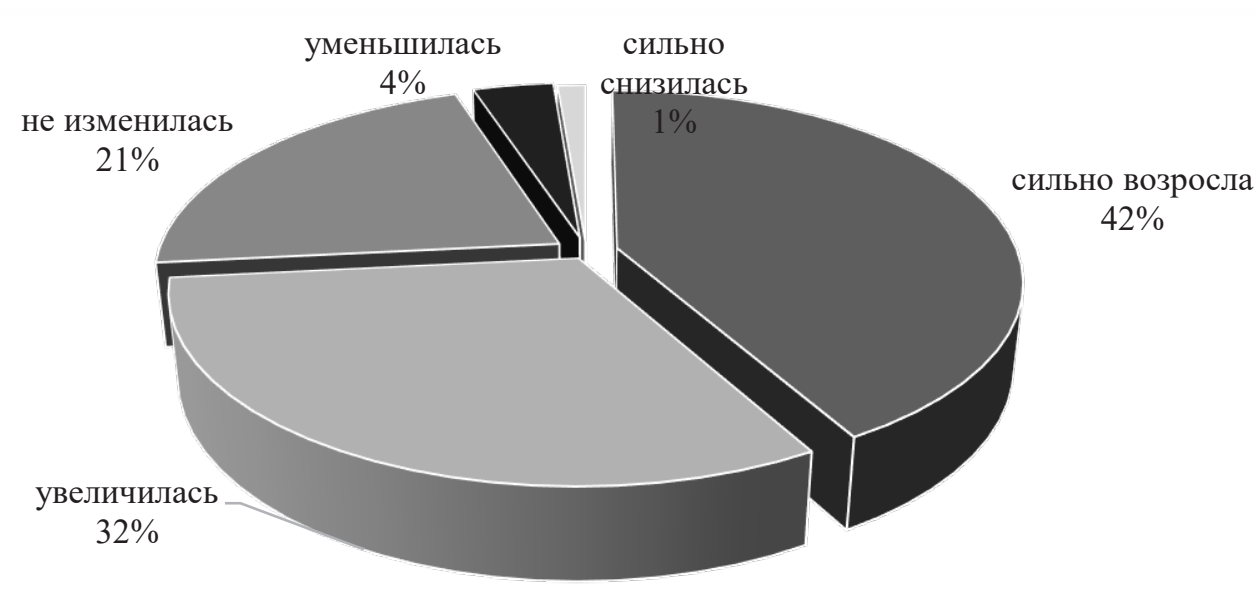

Рисунок 2. Изменения уровня нагрузки студентов в период пандемии

чем, предлагалось оценить уровень квалификации профессорско-преподавательского состава в данном вопросе (рис. 3).

Результаты данного вопроса весьма неоднозначны. Преподаватели, как и студенты, оказались не полностью готовыми к резкому переходу на дистанционный вид работы. Конференции на платформе Zoom, Google meet и других платформ, могли освоить далеко не все, $10 \%$ опрошенных считают, что уровень квалификации преподавателей в этом вопросе оказался очень низким, но, тем не менее, довольно большое количество студентов, а именно, 92 человека, что соответствует $46 \%$ опрошенных, считают уровень квалификации преподавателей достойным.

С целью определения соответствия требований способностям студентов был задан вопрос, направленный на оценку понимания ими принципов работы и особенностей курсов в дистанционном формате (рис. 4).

Курсы в дистанционном формате, судя по данным диаграммы, были практически не понятны для большинства студентов. Было сложно разобраться и вникнуть в новые для них условия. Но, все же, некоторая часть опрошенных посчитала достаточно ясными предлагаемые курсы. Для 8\% было совершенно понятно, как справляться с данным видом обучения, но смотря на это, смело можно сдать вывод, что положение являлось весьма затрудненным.

Также было выяснено, что дистанционное обучение, больше походит на систему самообразования. За это проголосовало целых $70 \%$ опрошенных.

Далее студентам предлагалось оценить эффективность работы технической поддержки университета. По результатам оценки больше половины респондентов отметили средний уровень работы технической поддержки, а $24 \%$ полагают, что техническая поддержка была эффективна.

И в заключение респонденты выделили основные проблемы, с которыми им пришлось сталкиваться во время обучения (рис. 5).

В данном вопросе $75 \%$ опрошенных уверены, что главная проблема - отсутствие должной

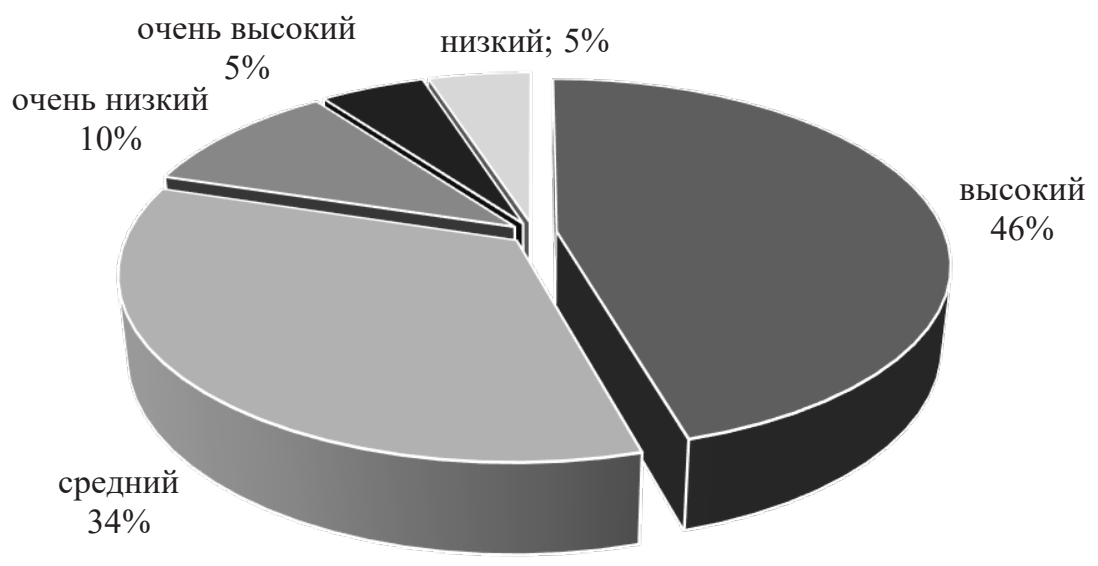

Рисунок 3. Уровень квалификации преподавателей при организации дистанционного обучения 


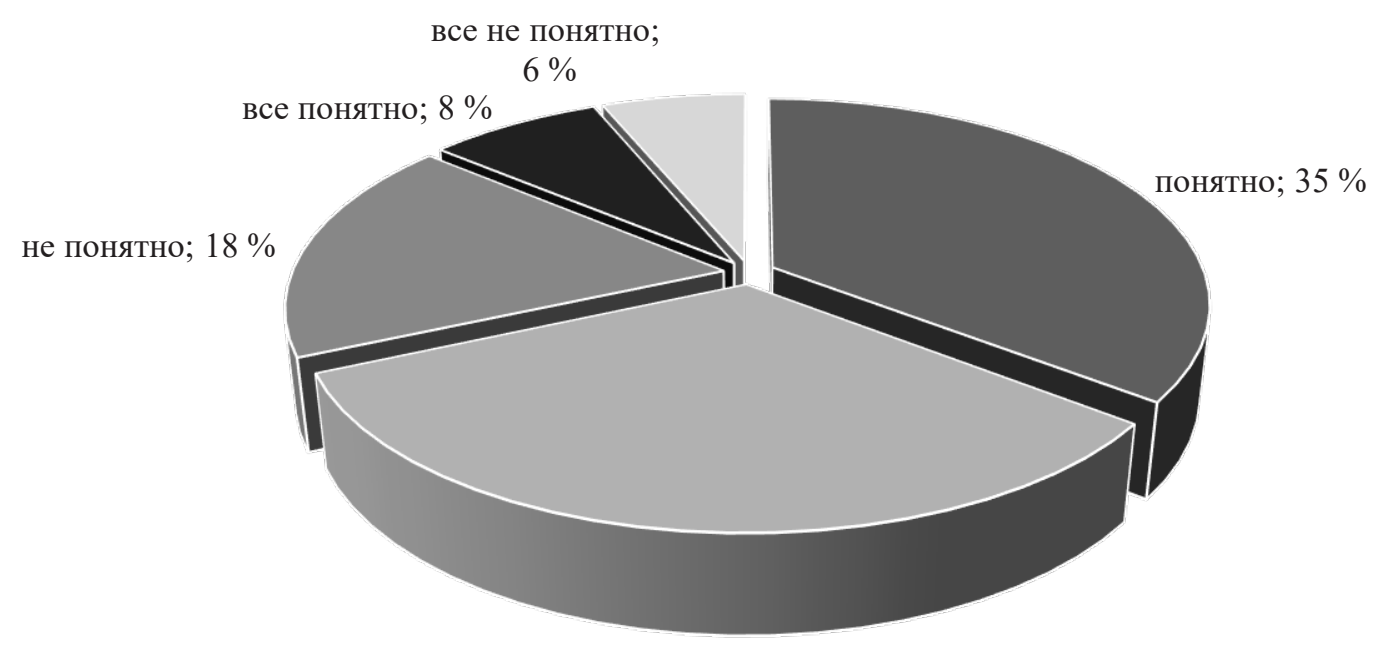

средне; $33 \%$

Рисунок 4. Понимание студентами принципов работы в дистанционном формате

процесс обучения был слишком утомительным

неполадки в системе (преподаватель не видит запроса на участие в вебинаре, срывы)

гость не получает балов за посещение в отличии от "участника"

предложенный вариант выполненной работы был отвергнут преподавателем

отсутствие должной инфраструктуры (нет микрофона, проблемы с установкой Adobe, google meet, Zoom

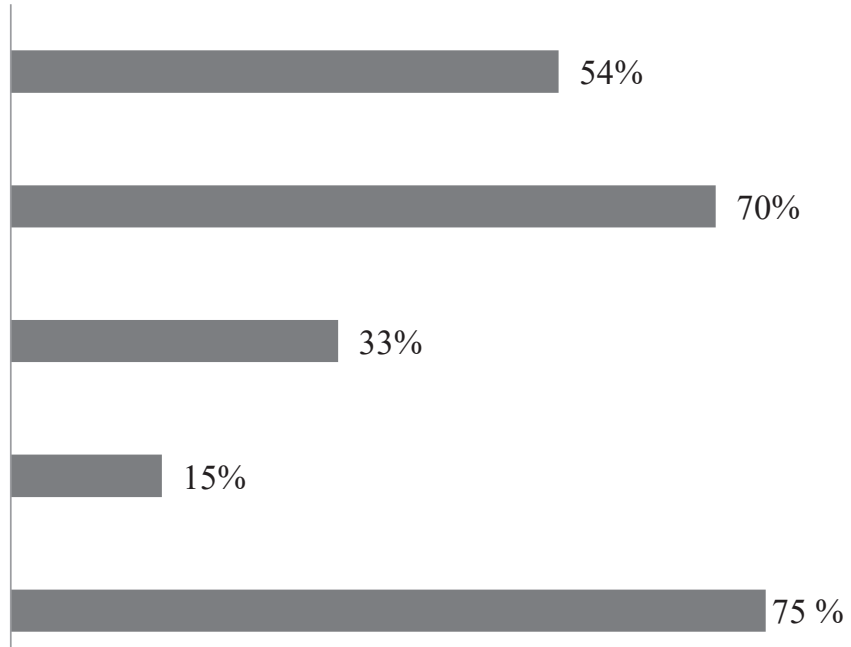

\section{Рисунок 5. Проблемы дистанционного обучения}

инфраструктуры; 70\% также уверены в том, что неполадки в системе являются проблемой дистанционного обучения; большинство выделяют проблему дистанционного обучения в том, что процесс обучения был слишком утомительным, $15 \%$ студентов обеспокоены в том, что преподаватель не рассмотрел предложенный студентом вариант работы.

В ходе проведенного анализа приходим к ряду выводов: эпидемиологическая ситуация повлияла на образовательный процесс: подготовка преподавателей и студентов была не достаточна, в результате чего возникли проблемы: трудности в освоении практических навыков, возникновение соблазна отложить работу до лучших времен, сложность встраивания мотивационных компонентов, нехватка навыков самоорганизации в период учебной деятельности, недостаток живого общения, отсутствие должностного контроля за процессом обучения и другие. Результаты опроса 200 студентов четко показали слабые места в образовательном процессе: дистанционный формат не удобен в использовании электронных ресурсов, низкая (недостаточная) квалификация преподавателей, недоступность и непонятность излагаемых требований курса студентам, отсутствие эффективной работы технической поддержки. 


\section{Библиографический список}

1. Балычевцева И.В., Чернышова О.Е., Самойленко И.Г., Конюшевская А.А., Кривошеева В.В., Герасименко В.В., Полесов Т. Р., Павлов Е. Н., Долинский В.В. Перспективы внедрения дистанционного обучения на факультете последипломного образования // Травма. 2019. № 4. С. 131-134.

2. Верхотин Д. Г. Дистанционное обучение в системе Moodle как средство обучения школьников // Вестник науки и образования. 2019. № 2-2 (56). С. 78-80.

3. Москаленко E.В., Овчаров А.В. Результаты внедрения в образовательный процесс средств электронного обучения в Алтайском государственном педагогическом университете // Преподаватель XXI век. 2019. № 2-1. С. 125-135.

4. Татаринов К. А. Проблемы и возможности дистанционного обучения студентов // БГЖ. 2019. № 1 (26). URL: https://cyberleninka.ru/article/n/problemy-i-vozmozhnosti-distantsionnogo-obucheniya-studentov (дата обращения: 04.12.2020).

5. Фадеев Е.В. Организационные и психологические проблемы дистанционного обучения // МНКО. 2017 . № 3 (64). URL: https://cyberleninka.ru/article/n/organizatsionnye-i-psihologicheskie-problemy-distantsionnogoobucheniya (дата обращения: 01.12.2020).

6. Чигинцева А.А. Актуальные проблемы дистанционного обучения // Скиф. 2018. № 3 (19). URL: https:// cyberleninka.ru/article/n/aktualnye-problemy-distantsionnogo-obucheniya (дата обращения: 04.11.2020). 